\title{
The gap between global issues and personal behaviors: pro-environmental behaviors of citizens toward climate change in Kaohsiung, Taiwan
}

\author{
Shis-Ping Lin
}

Received: 20 January 2012 / Accepted: 12 April 2012 /Published online: 28 April 2012

(C) The Author(s) 2012. This article is published with open access at Springerlink.com

\begin{abstract}
Taiwan ranks 22nd worldwide in greenhouse gas emissions. One-third of these emissions come from the city of Kaohsiung, Taiwan. To mitigate global warming, the Taiwanese government and non-governmental organizations (NGOs) of environmental protection have promoted a series of energy conservation methods based on citizens' proenvironmental behaviors. This research sorts these pro-environmental behaviors into five categories: diet, clothing, housing, transport, and recreation; further, it assesses them empirically by applying the theory of planned behavior (TPB) to a survey of 223 Kaohsiung residents. With the application of structural equation modeling, the indicators for each of these five models showed a good fit to the TPB, with goodness-of-fit (GFI) and adjusted goodness-of-fit (AGFI) values of 0.8 and above, comparative fit index (CFI) of 0.9 and above, and root mean square error of approximation (RMSEA) below 0.08. From these results, this research found that attitudes toward global warming influence citizens' proenvironment behavioral intentions; in particular, perceived behavior control played an important role in the model. This research suggests that people will accept proenvironmental behaviors if they perceive evidence of the usefulness and convenience of these behaviors. "Keep it simple" might be a good byword for promoting energy conservation methods. Nevertheless, it seems that it will be hard to change citizens' appetite or travel habits to mitigate global warming without providing clear, strong incentives.
\end{abstract}

Keywords Behavior C Climate change - Global warming $\cdot$ Mitigation · Pro-environmental behavior $\cdot$ Theory of planned behavior

\section{Introduction}

Around 1750, as the industrial revolution started in Europe, Earth's atmosphere contained about 280 ppm of carbon dioxide $\mathrm{CO}_{2}$, the overall amount of greenhouse gases (GHGs) has

S.-P. Lin $(\square)$

Institute of Public Affairs Management, National Sun Yat-sen University, No. 70, Lienhai Rd., Kaohsiung 80424 Taiwan, Republic of China

e-mail: splin@nuk.edu.tw 
topped $379 \mathrm{ppm} \mathrm{CO}_{2 \mathrm{e}}$ in 2005 , and the figure is rising by $1.4-1.9 \mathrm{ppm}$ annually (IPCC 2007). Scientists believe the Earth's average temperature must be kept to less than a $2{ }^{\circ} \mathrm{C}$ rise over pre-industrial levels and that a $50 \%$ chance exists of keeping to a $2^{\circ} \mathrm{C}$ rise if the total GHG concentration remains below 450 ppm (Kirby 2008). Therefore, the ultimate objective of the United Nations Framework Convention on Climate Change (UNFCCC) is to stabilize GHG concentrations in the atmosphere at a level, which should be achieved within a time frame sufficient to allow ecosystems to adapt naturally to climate change.

Most mitigation or adaptation strategies for climate change have been directed toward long-term options such as inducing new low-carbon technologies or creating cap-and-trade regimes for emissions. However, Dietz et al. (2009) emphasized that household sector is one of the major emitters of GHG, the direct energy use by households accounts for approximately $38 \%$ of overall $\mathrm{CO}_{2}$ emissions in the U.S., or approximately 626 million metric tons of carbon in 2005; this is approximately $8 \%$ of global emissions and more than the emissions of any other country except China (Dietz et al. 2009).

The population of Taiwan is about 23 million, and average per capita emission of $\mathrm{CO}_{2}$ is about $11.1 \mathrm{t}$, far exceeding global per capita emissions of $3.96 \mathrm{t}$; direct energy use by households accounted for approximately 27 million metric tons of carbon in 2000 and 32 million in 2010 (Taiwanese Bureau of Energy 2011).

Most people recognize that climate change and sustainability are important problems, but few citizens engage in greenhouse gas mitigating behaviors (Gifford 2011). Szerszynski (2007) notes the irony of the gap between professed environmental values and environmental behavior. Gifford (2011) called psychological barriers a "Dragon of inaction" which impedes the exercise of pro-environmental behavior, and O'Riordan (2009) argued that some carbon-reducing behaviors are so frictional, that is why humans seem to be hard-wired for immediate danger but soft-wired for long-term threats.

Therefore, one of the commitments of the UNFCCC is that all countries shall promote and cooperate in education and public awareness related to climate change and encourages the widest participation in this process, involving NGOs as well. Acting upon the UNFCCC commitment, the Taiwanese government and NGOs of environmental protection have begun promoting a series of energy-saving and carbon-reduction methods based on proenvironmental behaviors.

Despite all this, research on pro-environmental behaviors usually focuses on a single subject, for example, water conservation intention (Lam 1999, 2006; Clark and Finley 2007), using public transport (Chen and Chao 2011; Tikir and Lehmann 2011), organic food consumption (Aertsens et al. 2009), and energy conservation behaviors (Scherbaum et al. 2008).

The present study sorts pro-environmental behaviors into five categories: diet, clothing, housing, transport, and recreation. Dietz et al. (2009) argue that individual and household behavioral change faces barriers, but more is known about how to overcome these barriers than is commonly recognized. So, the goals of this study are 1) to recognize the proenvironmental behaviors of Kaohsiung citizens after several years of promoting public awareness of climate change, and 2) to determine the key factors that influence these proenvironmental behaviors significantly.

Theory of Planned Behavior (TPB) has been applied successfully to a wide range of human behaviors (Brown et al. 2010). The present study covers the pro-environmental behaviors that the Taiwanese government and Non-Governmental Organizations (NGOs) have been promoting, using TPB to examine them. 


\section{Literature review}

Pro-environmental behavior is probably best viewed as a mixture of self-interest and concern for other people, the next generation, other species, whole ecosystems, or the global climate itself (Bamberg and Möser 2006). McAndrew (1993) indicate that, though theory is very important in environmental psychology or behavioral research, there is no one theory that covers all environmental issues in an analysis of pro-environmental behavior. The (TPB; Ajzen and Madden 1986) and value-belief-norm (VBN) theory (Stern 2000) are often used to examine proenvironmental behavior. While TPB focuses on self-interest and rational choice deliberation, VBN is grounded in values and moral norms (Kaiser et al. 2005).

VBN is the integration of the value theory, the new environmental paradigm (Dunlap and Van Liere 1978), and Schwartz's (1977) theory of norm activation (Stern 2000). In VBN, "values" reflect the objects or principles that individuals view as important, "beliefs" reflect individuals' overall belief patterns and views of the world, and "norms" reflect individuals' personal rules and felt obligations to act in a particular manner (Scherbaum et al. 2008)

TPB is an extension of the theory of reasoned action, TRA (Ajzen and Fishbein 1980; Fishbein and Ajzen 1975). In this theory, attitudes toward behavior, subjective norms with respect to behavior, and perceived behavioral control are usually found to predict behavioral intentions. Intentions, in combination with perceived behavioral control, can explain variance of behavior (Ajzen and Manstead 2007).

Analyzing pro-environmental behaviors based on previous research on TPB, Aertsens et al. (2009) integrate value theory and TPB to look at personal determinants of organic food consumption; they conclude that organic food purchases are positively and significantly related to intentions. Regarding water conservation behaviors, TPB predicts intention to save water, and TPB variables show a positive, significant correlation with water conservation intention (Lam 1999, 2006; Clark and Finley 2007), but TPB was less successful in predicting intention to install water-efficient appliances (Lam 1999).

As for energy consumption for transportation, the travel-mode choice of student passengers has a good model fit to TPB (Klöckner and Blöbaum 2010). TPB also explained intention to use public transport; attitude and subjective norm influenced intention (Tikir and Lehmann 2011). On the other hand, Kerr et al. (2010) found that the behavioral intention as assessed by TPB was the strongest predictor of private vehicle usage. To go further, Chen and Chao (2011) found that habitual behavior hinders an individual's intention to switch from a private vehicle to public transport.

Households not only use energy in direct ways (e.g., gas, electricity, and fuel) but also in indirect ways (e.g., consumption and disposal of goods). Applying the TPB, Abrahamse and Steg (2009) find that energy use was mainly determined by sociodemographic variables: households with higher incomes, or greater in size tend to use more energy, whereas saving household energy appears to be associated with psychological factors.

Besides TPB, Scherbaum et al. (2008) applied VBN to the energy-conservation behaviors of employees, and found that personal norms significantly predicted behavioral intentions and energy-conservation behaviors.

Contrasting TPB and VBN regarding their ability to explain pro-environmental behaviors, Kaiser et al. (2005) found that the TPB covered its concepts more fully, in terms of proportions, in explaining variance in energy conservation behavior. More importantly, the fit statistics revealed that TPB depicts the relations among its concepts appropriately, whereas the VBN model does not. Fielding et al. (2008) also found that, whether private or public environmental actions, are being considered, TPB is an effective model for identifying the predictors of pro-environmental behaviors. 


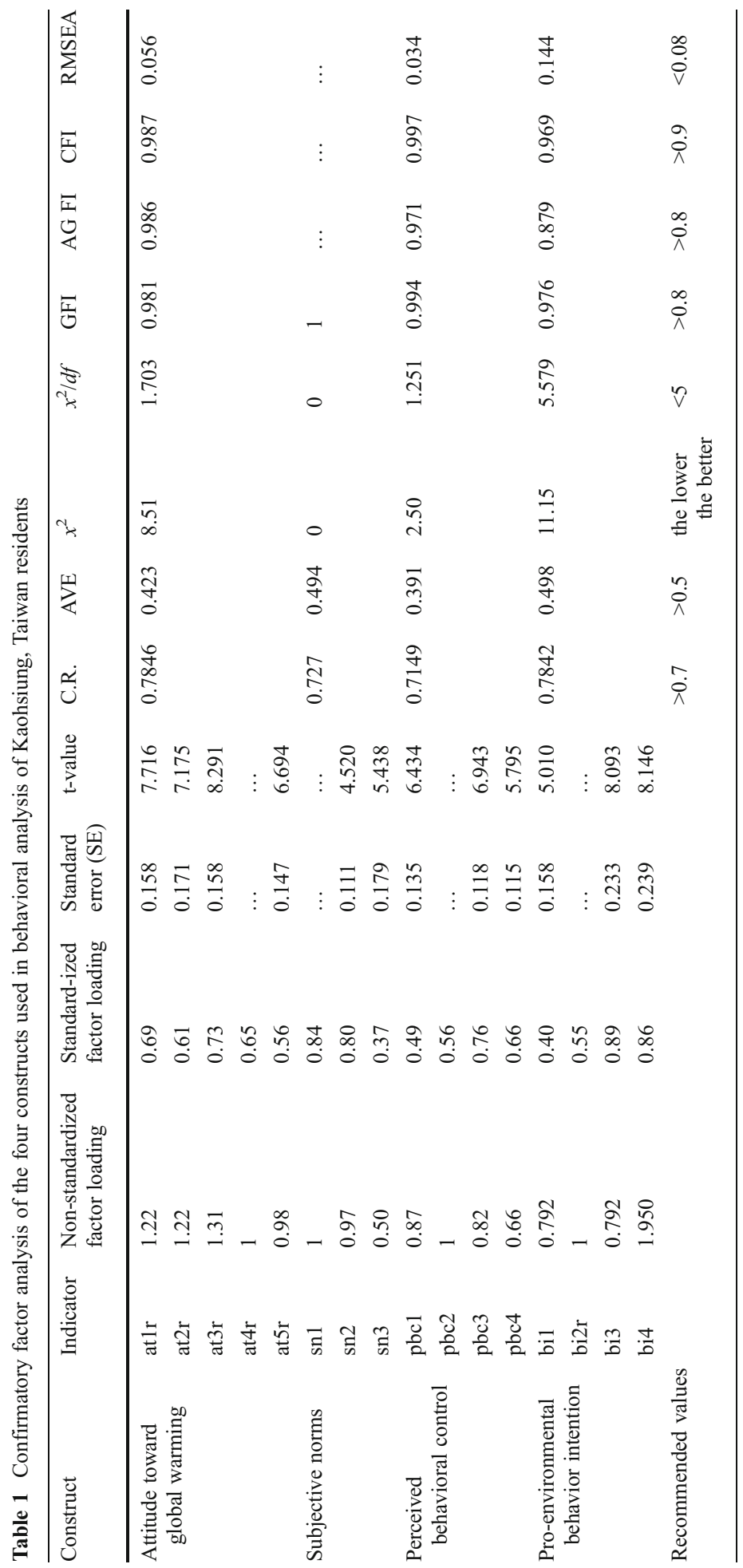




\section{Methods}

Kaohsiung is the most important industrial metropolis in Taiwan. Annual average per capita emission of $\mathrm{CO}_{2}$ in Kaohsiung is $26.3 \mathrm{t}$ (Environmental Protection Bureau of Kaohsiung City Government 2009). The majority of $\mathrm{CO}_{2}$ emissions in Kaohsiung come from the industrial sector (68\%), followed by the household and commercial sectors $(23 \%)$. Using the TPB model, this study aimed to clarify the pro-environmental behavior of Kaohsiung residents, living in an era of climate change in a high-emission city.

\subsection{Research model}

This study used five constructs of TPB to design and develop the questionnaire. "Attitude towards environment" indicated residents' views about global warming and their awareness of climate change. "Subjective norms" indicated the views on energy conservation of influential people such as family and friends. "Perceived behavioral control" indicated residents' perceived capacity to implement conservation methods. "Behavioral intention" indicated residents' willingness to engage in energy conservation. "Behavior" aims to understand whether, and to what extent, residents have previously engaged in energy conservation.

Table 2 Constructs and corresponding items in the behavioral analysis of Kaohsiung, Taiwan residents

\begin{tabular}{|c|c|c|}
\hline Constructs & Items & \\
\hline \multirow[t]{5}{*}{$\begin{array}{l}\text { Attitudes toward } \\
\text { global warming }\end{array}$} & at1r & $\begin{array}{l}\text { Current global warming is just a natural phenomenon, } \\
\text { instead of manmade. * }\end{array}$ \\
\hline & at $2 \mathrm{r}$ & $\begin{array}{l}\text { I think everyone is over-emphasizing climate change } \\
\text { and global warming. * }\end{array}$ \\
\hline & at $3 \mathrm{r}$ & The possible extinction of polar bears has no relation to my life. * \\
\hline & at4r & $\begin{array}{l}\text { I think that individual implementation of energy conservation } \\
\text { methods is meaningless. * }\end{array}$ \\
\hline & at $5 \mathrm{r}$ & $\begin{array}{l}\text { Poverty and infectious diseases are more serious } \\
\text { than global warming. * }\end{array}$ \\
\hline \multirow[t]{3}{*}{ Subjective norms } & sn1 & My family often discusses climate change or global warming. \\
\hline & $\operatorname{sn} 2$ & My peers often discuss climate change or global warming. \\
\hline & $\operatorname{sn} 3$ & $\begin{array}{l}\text { If I do not implement energy conservation methods, } \\
\text { my peers may criticize me. }\end{array}$ \\
\hline \multirow[t]{4}{*}{$\begin{array}{l}\text { Perceived behavioral } \\
\text { control }\end{array}$} & $\mathrm{pbc1}$ & $\begin{array}{l}\text { The energy conservation methods promoted by government } \\
\text { are easy for me. }\end{array}$ \\
\hline & $\mathrm{pbc} 2$ & $\begin{array}{l}\text { The energy conservation methods promoted by } \\
\text { NGOs are easy for me. }\end{array}$ \\
\hline & pbc3 & I can obtain information of energy conservation methods easily. \\
\hline & pbc4 & I can determine the suitable energy conservation methods easily. \\
\hline \multirow[t]{4}{*}{$\begin{array}{l}\text { Pro-environmental } \\
\text { behavior intention }\end{array}$} & bi1 & $\begin{array}{l}\text { I am willing to implement the energy conservation methods } \\
\text { promoted by the government }\end{array}$ \\
\hline & bi $2 \mathrm{r}$ & $\begin{array}{l}\text { I am not willing to change my lifestyle to counteract global } \\
\text { warming and climate change. } *\end{array}$ \\
\hline & bi3 & I am willing to implement pro-environmental methods for my family. \\
\hline & bi4 & I am willing to implement pro-environmental methods for my peers. \\
\hline
\end{tabular}

* Reverse questions 


\subsection{Sampling}

This study selected a sample of 225 individuals based on the ratio of each administrative area's population to the total population of Kaohsiung. Quota sampling was used, and city residents conducting business at each household registration office in Kaohsiung City were targeted as samples. The researchers used questionnaires and face-to-face interviews to collect information.

\subsection{Research design}

The present assumptions are 1) the sample data fit the TPB model; 2) ATTitude towards global warming (ATT), Subjective Norm (SN), and Perceived Behavioral Control (PBC) influence pro-environmental Behavioral Intention (BI); and, 3) PBC and pro-environmental (BI) influenced pro-environmental behavior (B) significantly.

Table 3 Categories of pro-environmental behavior in analysis of Kaohsiung, Taiwan residents

\begin{tabular}{|c|c|c|c|}
\hline $\begin{array}{l}\text { Categories of pro- } \\
\text { environmental behavior }\end{array}$ & $\begin{array}{l}\text { Standardized } \\
\text { factor loading }\end{array}$ & Items & \\
\hline \multirow[t]{3}{*}{ Diet } & \multirow[t]{3}{*}{0.81} & b1 & I have reduced my intake of meat over the last month. \\
\hline & & $\mathrm{b} 2$ & $\begin{array}{l}\text { I buy Taiwan-produced fruit and avoid buying imported } \\
\text { fruit (e.g., cherries). }\end{array}$ \\
\hline & & $\mathrm{b} 3 \mathrm{r}$ & $\begin{array}{l}\text { I often store food in my refrigerator that is past its } \\
\text { use by date. } *\end{array}$ \\
\hline \multirow[t]{3}{*}{ Clothing } & \multirow[t]{3}{*}{0.73} & b4 & $\begin{array}{l}\text { In summer I wear light, cool clothing to reduce my use } \\
\text { of air conditioning. }\end{array}$ \\
\hline & & b5 & $\begin{array}{l}\text { I carry a handkerchief and minimize my use } \\
\text { of tissues paper. }\end{array}$ \\
\hline & & b6 & $\begin{array}{l}\text { I use fans or open windows, minimizing my use } \\
\text { of air conditioning. }\end{array}$ \\
\hline \multirow[t]{4}{*}{ Housing } & \multirow[t]{4}{*}{0.79} & $\mathrm{~b} 7 \mathrm{r}$ & $\begin{array}{l}\text { I am more concerned about price when I purchase } \\
\text { electrical appliances.* }\end{array}$ \\
\hline & & b8 & $\begin{array}{l}\text { I purchase electrical appliances that have } \\
\text { energy saving labels. }\end{array}$ \\
\hline & & b9 & I turn lights and water taps off as much as possible. \\
\hline & & b10 & I unplug appliances that are temporarily not in use. \\
\hline \multirow[t]{3}{*}{ Transport } & \multirow[t]{3}{*}{0.04} & $\mathrm{~b} 11 \mathrm{r}$ & $\begin{array}{l}\text { My primary mode of commute is a } \\
\text { motor scooter or a car.* }\end{array}$ \\
\hline & & $\mathrm{b} 12 \mathrm{r}$ & I use elevators and rarely use stairs.* \\
\hline & & b13 & $\begin{array}{l}\text { I support an increase of fuel tax to reduce the use } \\
\text { of fossil fuels. }\end{array}$ \\
\hline \multirow[t]{5}{*}{ Recreation } & \multirow[t]{5}{*}{0.78} & b14 & I carry my own water bottle with me when I go out. \\
\hline & & b15 & $\begin{array}{l}\text { I carry a convenience bag with me when I go out, } \\
\text { in case to purchase goods. }\end{array}$ \\
\hline & & b16 & I do not purchase bottled water. \\
\hline & & $\mathrm{b} 17 \mathrm{r}$ & I am unable to consider about recycle when I go out.* \\
\hline & & b18 & I carry my own chopsticks when I go out. \\
\hline
\end{tabular}

*Reverse questions 
Table 4 Model fitness analysis of TPB in analysis of Kaohsiung, Taiwan residents

\begin{tabular}{lllllll}
\hline & $x^{2}$ & $x^{2} / d f$ & GFI & AGFI & CFI & RMSEA \\
\hline Pro-environmental behavior in dietary & 227.936 & 1.583 & 0.900 & 0.869 & 0.924 & 0.051 \\
Pro-environmental behavior in clothing & 232.214 & 1.613 & 0.901 & 0.870 & 0.929 & 0.053 \\
Pro-environmental behavior in housing & 269.729 & 1.665 & 0.887 & 0.854 & 0.907 & 0.055 \\
Pro-environmental behavior in transport & 206.679 & 1.453 & 0.912 & 0.883 & 0.938 & 0.044 \\
Pro-environmental behavior in recreation & 287.540 & 1.539 & 0.892 & 0.862 & 0.924 & 0.049 \\
Recommended values & & $<5$ & $>0.8$ & $>0.8$ & $>0.9$ & $<0.08$ \\
\hline
\end{tabular}

This research conducted a Confirmatory Factor Analysis (CFA) to examine whether each construct could be explained by its indicators (observed variables); then, Structural Equation Modeling (SEM) was utilized to examine the model fitness and test causal relationships. Path Analysis was used to identify the influence of constructs on the model.

\section{Results}

Among the 223 valid respondents to this study, females $(53.4 \%)$ outnumbered the males (46.6\%). Respondents aged 30-39 (27.4\%) accounted for the largest age category, followed by those aged 20-29 (22.9\%). The majority of respondents had a junior college level education (48.9\%). Regarding marital status, $60.5 \%$ of the respondents were married, while $57 \%$ had children. Regarding personal monthly disposable income, the largest group of respondents were in the TWD $\$ 15,000$ to 20,000 (US\$500 to 660) category. Finally, regarding religious beliefs, the category "no religious beliefs" included the most respondents (32.3\%), followed by Buddhism (21.1\%) and Taoism (12.6\%).

\subsection{Analysis of model fit}

A confirmatory factor analysis was conducted. Hair et al. (2006) suggest that a critical ratio (CR) of 0.7 and above indicates good composite reliability; they also suggest that average variance extracted (AVE) value of 0.5 and above indicates a good convergent validity. Doll et al. (1994) suggest that goodness-of-fit (GFI) and adjusted goodness-of-fit (AGFI) values of 0.8 and above indicate a reasonable fit. Byrne (2001) suggests that a comparative fit index (CFI) value of 0.9 and above indicated a well-fitting model. Byrne also suggests that a rootmean-square error of approximation (RMSEA) value below 0.08 indicated a comparatively

Table 5 Path Analysis of pro-environmental behavior in the diet model of Kaohsiung, Taiwan residents

\begin{tabular}{lllllll}
\hline & & & Estimate & S.E. & C.R. & P \\
\hline BI & $<---$ & SN & 0.004 & 0.038 & 0.105 & 0.916 \\
BI & $<--$ & ATT & 0.109 & 0.043 & 2.534 & 0.011 \\
BI & $<--$ & PBC & 0.270 & 0.080 & 3.368 & $* * *$ \\
B_diet & $<---$ & PBC & 0.032 & 0.061 & 0.518 & 0.605 \\
B_diet & $<--$ & BI & 0.025 & 0.049 & 0.497 & 0.619 \\
\hline
\end{tabular}

S.E.: standard error of regression weight; C.R.: critical ratio for regression weight; P: level of significance for regression weight 
Table 6 Path analysis of pro-environmental behavior in the clothing model of Kaohsiung, Taiwan residents

\begin{tabular}{lllllll}
\hline & & & Estimate & S.E. & C.R. & P \\
\hline BI & $<---$ & SN & 0.010 & 0.038 & 0.267 & 0.789 \\
BI & $<--$ & ATT & 0.113 & 0.043 & 2.598 & 0.009 \\
BI & $<--$ & PBC & 0.270 & 0.079 & 3.397 & $* * *$ \\
B_cloth & $<--$ & PBC & 0.229 & 0.155 & 1.473 & 0.141 \\
B_cloth & $<---$ & BI & 0.656 & 0.248 & 2.647 & 0.008 \\
\hline
\end{tabular}

good fit. Joreskog and Sorbom (1993) suggests that a $x^{2} / d f$ value below 5 indicates that the model is acceptable. Most of the indicators in this study show a good fit to the corresponding TPB constructs in Table 1, meaning that all of the indicators (observed variables) reflected the constructs (latent variables) effectively (shown in Table 2). This study classified proenvironmental behaviors into five categories (shown in Table 3). Structural equation modeling (SEM) was conducted to analyze goodness of fit of these five models; each indicator showed that the sample data fit the TPB model fairly well, as shown in Table 4.

\subsection{Model of pro-environmental behavior in diet}

In the model of pro-environmental behavior in diet, ATT and PBC influenced proenvironmental behavior BI significantly $(p<.05)$. However, the influence of BI and PBC on pro-environmental dietary behaviors was not significant (shown in Table 5), meaning that asking people to consume less meat and more vegetables or purchase more local food instead of imported food for the purpose of mitigating climate change may be useless, even though they have an awareness of climate change and the intention to change their lifestyle to counteract it.

\subsection{Model of pro-environmental behavior in clothing}

This model indicates that ATT and PBC significantly influence BI $(p<.05)$, and indirectly influence clothing choices $(p<.05)$ (as shown in Table 6). Therefore, encouraging citizens not to wear suits or formal clothing in order to reduce the need for air-conditioning and mitigate climate change had statistically significant results.

\subsection{Model of pro-environmental behavior in housing}

Although the influence of $\mathrm{BI}$ on pro-environmental behavior in housing was not statistically significant, the PBC's influence on pro-environmental behavior in housing

Table 7 Path analysis of pro-environmental behavior in the housing model of Kaohsiung, Taiwan residents

\begin{tabular}{lllllll}
\hline & & & Estimate & S.E. & C.R. & P \\
\hline BI & $<--$ & SN & 0.005 & 0.038 & 0.139 & 0.889 \\
BI & $<--$ & ATT & 0.110 & 0.043 & 2.551 & 0.011 \\
BI & $<--$ & PBC & 0.264 & 0.077 & 3.440 & $* * *$ \\
B_housing & $<--$ & PBC & 0.397 & 0.124 & 3.202 & 0.001 \\
B_housing & $<--$ & BI & 0.274 & 0.176 & 1.554 & 0.120 \\
\hline
\end{tabular}


Table 8 Path analysis of pro-environmental behavior in the transport model of Kaohsiung, Taiwan residents

\begin{tabular}{lllllll}
\hline & & & Estimate & S.E. & C.R. & P \\
\hline BI & $<--$ & SN & 0.008 & 0.037 & 0.211 & 0.833 \\
BI & $<--$ & ATT & 0.108 & 0.042 & 2.557 & 0.011 \\
BI & $<--$ & PBC & 0.267 & 0.078 & 3.417 & $* * *$ \\
B_trans & $<--$ & PBC & 0.147 & 0.122 & 1.206 & 0.228 \\
B_trans & $<--$ & BI & 0.117 & 0.164 & 0.715 & 0.475 \\
\hline
\end{tabular}

was significant $(p<.05)$ (as shown in Table 7). These results show that letting citizens practice energy conservation methods is more useful than just telling them. Encouraging people to use energy-saving light bulb (e.g., LED light bulb), or turn off the lights when they are not in use will reduce the power bill, which will encourage the people to act further.

\subsection{Model of pro-environmental behavior in transport}

In this model, ATT and PBC influenced BI significantly $(p<.05)$, but the influence of BI on pro-environmental behavior in transport was not significant (as shown in Table 8). The results indicate that the majority of citizens use private vehicles (scooters or cars) as their primary mode of transport, instead of taking the bus or using a mass rapid transit (MRT) system, meaning that asking people to switch from private vehicles to public transport for the purpose of mitigating climate change may be useless.

\subsection{Model of pro-environmental behavior in recreation}

In table 9, the influence of BI on pro-environmental behavior in recreation was not significant; however, PBC's influence on pro-environmental behavior in recreation was statistically significant $(p<.05)$; this result shows that the existence more convenient and acceptable methods of pro-environmental behaviors in recreation may encourage people to act.

\section{Discussion and conclusion}

The sample data in this study, which was based on the TPB model, fit the model fairly well; meanwhile, the study found that, although Kaohsiung citizens are aware of climate change and their intention to practice pro-environmental behaviors is high, it seems hard for them to

Table 9 Path analysis of pro-environmental behavior in the recreation model of Kaohsiung, Taiwan residents

\begin{tabular}{lllllll}
\hline & & & Estimate & S.E. & C.R. & P \\
\hline BI & $<--$ & SN & -0.001 & 0.039 & -0.030 & 0.976 \\
BI & $<--$ & ATT & 0.108 & 0.043 & 2.523 & 0.012 \\
BI & $<--$ & PBC & 0.269 & 0.080 & 3.382 & $* * *$ \\
B_recreat & $<--$ & PBC & 0.210 & 0.089 & 2.372 & 0.018 \\
B_recreat & $<--$ & BI & 0.110 & 0.100 & 1.101 & 0.271 \\
\hline
\end{tabular}


change their appetites or travel habits to cool down global warming. Interpreting this as a manifestation of the gap between people's awareness and their behavior, and assuming that habitual behavior seems to be hindering the intention (Chen and Chao 2011) may be a reasonable way of understanding this point.

This study also found that perceived behavioral control plays an important role in its research model; it influenced pro-environmental behaviors significantly in major cases, while the influence of the intention to practice pro-environmental behaviors was not significant. Therefore, this study suggests that it is useful to encourage citizens to accept energy-saving methods by letting them experience those methods. For example, the government could subsidize the purchase of energy-saving appliances (e.g., energy-saving lights) instead of just promoting climate change and asking citizens to buy them. Once people see the benefits (e.g., saving the power bill), the willingness to purchase energysaving appliances might increase.

The present findings also confirm previous evidence that pro-environmental methods should be easy to connect to the decision at hand and that programs need to be designed for convenience and simplicity (Stern et al. 2010). This research suggests that more convenient and accepted methods of pro-environmental behaviors (e.g., carrying a personal water bottle, travelling chopsticks, or convenience bags; not buying bottled water) may encourage people to act more positively. "Keep it simple" in this sense might be a good byword for energy conservation.

Subjective norms were not salient in this study, according to the TPB model, which means that the views of the person who respondents concern (e.g., family and friends) might not influence them. It is ultimately left to the people themselves to decide whether to practice pro-environmental behaviors.

Some of the pro-environmental behaviors evaluated in this study might be suitable only for Asian countries (e.g., carrying personal chopsticks instead of using disposable chopsticks); this is a potential limitation of this study. However, this study emphasizes the concept of not using disposable goods. A modification of the TPB model to increase its application by giving it a broader interpretation of pro-environmental behaviors may be a useful direction for future research.

Open Access This article is distributed under the terms of the Creative Commons Attribution License which permits any use, distribution, and reproduction in any medium, provided the original author(s) and the source are credited.

\section{References}

Abrahamse W, Steg L (2009) How do socio-demographic and psychological factors relate to households' direct and indirect energy use and savings? J Econ Psychol 30:711-720

Aertsens J, Verbeke W, Mondelaers K, Huylenbroeck GV (2009) Personal determinants of organic food consumption: a review. Br Food J 111(10):1140-1167

Ajzen I, Fishbein M (1980) Understanding attitudes and predicting social behavior. Prentice Hall, Englewood Cliffs, NJ

Ajzen I, Madden TJ (1986) Prediction of goal-directed behavior: attitude, intentions, and perceived behavioral control. J Exp Soc Psychol 22:453-474

Ajzen I, Manstead ASR (2007) Changing health-related behavior: an approach based on the theory of planned behavior. The scope of social psychology: theory and application. Psychology Press, New York

Bamberg S, Möser G (2006) Twenty years after Hines, Hungerford, and Tomera: a new meta-analysis of psycho-social determinants of pro-environmental behavior. J Environ Psychol 27:14-25 
Brown TJ, Ham SH, Hughes M (2010) Picking up litter: an application of theory-based communication to influence tourist behavior in protected areas. J Sustain Tour 18(7):879-900

Byrne BM (2001) Structural equation modeling with Amos Basic. Lawrence Erlbaum Associates, Mahwah, New Jersey

Chen CF, Chao WH (2011) Habitual or reasoned? Using the theory of planned behavior, technology acceptance model, and habit to examine switching intentions toward public transit. Transport Res $\mathrm{F}$ $14: 128-137$

Clark WA, Finley JC (2007) Determinants of water conservation intention in Blagoevgrad, Bulgaria. Soc Nat Resour 20:613-627

Dietz T, Gardner GT, Gilligan J, Stern PC, Vandenbergh MP (2009) Household actions can provide a behavioral wedge to rapidly reduce US carbon emissions. Proc Natl Acad Sci U S A 106(44):1845218456

Doll WJ, Xia W, Torkzadeh G (1994) A confirmatory factor analysis of the end-user computing satisfaction instrument. MIS Q 18(4):357-369

Dunlap R, Van Liere K (1978) The new environmental paradigm: a proposed measuring instrument and preliminary results. J Environ Educ 9:10-19

Environmental Protection Bureau, Kaohsiung City Government (2009) Introduction of environmental protection administration in Kaohsiung City (in Mandarin)

Fielding KS, McDonald R, Louis WR (2008) Theory of planned behavior, identity and intentions to engage in environmental activism. J Environ Psychol 28:318-326

Fishbein M, Ajzen I (1975) Belief, attitude, intention, and behavior: an introduction to theory and research. Reading, MA

Gifford R (2011) The dragons of inaction - psychological barriers that limit climate change mitigation and adaptation. Am Psychol 66(4):290-302

Hair JF, Black WC, Babin BJ, Anderson RE, Tatham RL (2006) Multivariate data analysis. Pearson Prentice Hall, New Jersey

IPCC (2007) Climate Change 2007: Synthesis Report. http://www.ipcc.ch/publications_and_data/ar4/syr/en/ contents.html. Cited 12 June 2011

Joreskog KG, Sorbom D (1993) LISREL 8: structural equation modeling with SIMPLIS TM command language. Scientific Software International, Inc., Chicago

Kaiser FG, Hubner G, Bogner FX (2005) Contrasting the theory of planned behavior with the value-beliefnorm model in explaining conservation behavior. J Appl Soc Psychol 35(10):2150-2170

Kerr A, Lennon A, Watson B (2010) The call of the road: factors predicting students' car travelling intention and behavior. Transportation 37:1-13

Kirby A (2008) Kick the habit—a UN guide to climate neutrality. UNEMG and UNEP/GRID, Arendal, Norway

Klöckner CA, Blöbaum A (2010) A comprehensive action determination model: toward a broader understanding of ecological behavior using the example of travel mode choice. J Environ Psychol 30:574-586

Lam SP (1999) Predicting intentions to conserve water from the theory of planned behavior, perceived moral obligation, and perceived water right. J Appl Soc Psychol 29(5):1058-1071

Lam SP (2006) Predicting intentions to save water: theory of planned behavior, response efficacy, vulnerability, and perceived efficiency of alternative solution. J Appl Soc Psychol 36(11):2803-2824

McAndrew FT (1993) Environmental psychology. Brooks/Cole, CA

O'Riordan T (2009) Why carbon-reducing behavior is proving so frictional. Environment 51(5): cover2

Scherbaum CA, Popovich PM, Finlinson S (2008) Exploring individual-level factors related to employee energy-conservation behaviors at work. J Appl Soc Psychol 38(3):818-835

Schwartz S (1977) Normative influences on altruism. In: Berkowitz L (ed) Advances in experimental social psychology, vol 10. Academic, New York, pp 221-279

Stern PC (2000) Toward a coherent theory of environmentally significant behavior. J Soc Issues 56(3):407424

Stern PC, Gardner GT, Vandenbergh MP, Dietz T, Gilligan JM (2010) Design principles for carbon emissions reduction programs. Environ Sci Technol 44(13):4847-4848

Szerszynski B (2007) The post-ecologist condition: irony as symptom and cure. Environ Polit 16(2):337-355

Taiwanese Bureau of Energy (2011) Our nation's $\mathrm{CO}_{2}$ emissions statistics and analysis (in Mandarin). Bureau of Energy, Ministry of Economic Affairs, Taiwan

Tikir A, Lehmann B (2011) Climate change, theory of planned behavior and value: a structural equation model with mediation analysis. Clim Chang 104:389-402

UNFCCC (United Nations Framework Convention on Climate Change) http://unfccc.int/essential_background/ convention/status_of_ratification/items/2631.php 